RAD Conference Proceedings, vol. 3, pp. 197-201, 2018

ISSN 2466-4626 (online) | DOI: 10.21175/RadProc.2018.42

www.rad-proceedings.org

\title{
OCCUPATIONAL EXPOSURE TO ELECTROMAGNETIC FIELD - TRANSPOSITION OF THE EUROPEAN POLICY
}

\author{
Michel Israel ${ }^{1,2}$, Mihaela Ivanova ${ }^{1}$, Victoria Zaryabova ${ }^{1}$, \\ Tsvetelina Shalamanova ${ }^{1^{*}}$, Petya Ivanova ${ }^{1}$
}

${ }^{1}$ National Centre of Public Health and Analyses, Sofia, Bulgaria

${ }^{2}$ Medical University-Pleven, Pleven, Bulgaria

\begin{abstract}
The health policy connected with electromagnetic fields' exposure of workers in Europe was developed on the basis of the ICNIRP Guidelines through the implementation of the Directive 2013/35/EC. The transposition of the $E U$ Directive into the national legislation is a large process including the implementation of an ordinance, training of employers and workers, occupational health services, specialists performing measurements. An additional activity is the development of standard methods of risk assessment for practical implementation valid for concrete occupations and workplaces. Special attention should be paid to the workplaces with magnetic resonance imaging.
\end{abstract}

Key words: Electromagnetic fields, exposure assessment, exposure limits, action levels

\section{INTRODUCTION}

The European Directive 2013/35/EC for protection of workers exposed to electromagnetic fields (EMFs) was developed on the basis of the Guidelines of the International Commission of NonIonizing Radiation Protection (ICNIRP) regarding exposure limits [1]-[3] There are several international organizations (NGOs) preparing and recommending exposure limits for EMFs as ICNIRP, the Institute of Electrical and Electronic Engineers (IEEE). Additionally, the European Committee for Electrotechnical Standardization (CENELEC), the International Electrotechnical Commission (IEC) recommends product standards, and also technical standards for requirements of measurement and exposure assessment. The World Health Organization (WHO) and the European Commission are working very closely with ICNIRP, and the main EU policy in this field was based on its recommendations and guidelines.

Following the entry into force of Directive 2004/40/EC of the European Parliament and of the Council of 29 April 2004 on the minimum health and safety requirements regarding the exposure of workers to the risks arising from physical agents (electromagnetic fields), serious concerns were expressed by stakeholders, in particular those from the medical community, as to the potential impact of the implementation of that Directive on the use of medical procedures based on medical imaging. This was the reason for the new proposal to be developed in the period $2011-2013$. The result was the Directive 2013/35/EU of the European Parliament and the Council repealing Directive 2004/40/EU.

Exposure limits for EMFs in Bulgaria exist since 1971. Two national standards were applied until 2011. The period from 2011 to 2016 was an "empty period" in which the workers in our country exposed to EMF were not protected. This is the main purpose for our Expert Advisory Board (EAB) created by the Ministry of Health to insist on the EU Directive to enter our legislation as soon as possible.

\section{PURPOSE}

The main objective of this paper is to present the difficulties concerning the process of the implementation of the EU Directive as a document providing health and safety of workers exposed to EMFs. This is achieved on the basis of the analysis of the quality of control of EMFs in Bulgaria including the level of transposition of the EU Directive into the national legislation, the competence of the control bodies, equipment available in the country, etc.

\section{OBJECTIVE AND METHODS}

The paper deals with the risk management and policy in the field of health and safety at work. It gives recommendations for further activities in this area, and an example of exposure assessment of EMF in magnetic resonance imaging (MRI) facilities in hospitals, as well.

\footnotetext{
*ts.shalamanova@gmail.com
} 


\section{ANALYSIS OF THE SITUATION}

\subsection{Legislation}

The EU Directive 2013/35/EC has been implemented into the national legislation through an Ordinance RD-07-5 for the minimal requirements for providing health and safety at work at risks by exposure to electromagnetic fields, 29 November 2016, State gazette No. 95. [4] It was in force by $1^{\text {st }}$ March 2017. According to this Ordinance, exposure limit values (ELVs) and action levels (ALs) were implemented for electric, magnetic and EMFs with frequencies up to $300 \mathrm{GHz}$. New physical parameters, new philosophy and approaches were accepted concerning the exposure and risk assessment of EMF in different occupations. Some of these parameters are not measurable, and calculations and modeling are very important in cases when measured values are close to or exceed the ALs.

Art. 15 of the Ordinance announces the possibility three Practical Guides to be used in the process of risk assessment by the employers, specialists performing measurement, control or evaluations, by the workers, trade unions, etc. [5]-[7].

\subsection{Competence}

Measurement and exposure assessment of EMF is an extremely difficult process because of many factors influencing its uncertainty.

Most of the problems are connected with the basic knowledge of the specialists performing measurements. They should have university degree based in physics or engineering, only in the field of measurement, metrology, electronics, energetic, radio, TV, communication but not in chemistry or other type of engineering on engines, agriculture, petrol, IT or others not connected directly with measurements of physical factors. Unfortunately, in our country most of the control bodies hire employees without basic knowledge in physics. Most of them do not understand the nature of EMF, how the sources irradiate electromagnetic energy, what happens in the working environment and how the worker is exposed, how the measuring device influences the field.

The other problem is that EMFs in a non-free environment (premises with reflecting and absorbing surfaces) - workplaces are very difficult to be calculated without any precise measurements because of near-field exposure, reflection and absorption, interference between different EMFs and frequencies, modulation, etc.

The third problem is that most of the control bodies follow the EU Standard 17020 for accreditation that requires only compliance with the action levels, and they don't analyze the problems and don't propose any prevention measures that are very important for such a difficult physical factor, also how to solve the problems with uncertainty.

The Ministry of Health through the National Centre of Public Health and Analyses (NCPHA), also through the Expert Advisory Board (EAB) on Non-
Ionizing Radiation Protection organize training courses very often for them but the results of the tests after the training are unsatisfactory because of the low level of basic knowledge in physics of trained people.

\subsection{Risk management policy}

Because of the absence of EMF regulation from 2011 to 2016, nobody was interested in health and safety of the workers exposed to EMF in Bulgaria. This led to the lack of trained specialists, adequate equipment for measurements, and experience in exposure and risk assessment in the country. The specialists from NCPHA insisted on the European practice based on ICNIRP Guidelines to be applied during the time of lack of any other legislation in our country but it was misunderstood by the administration.

In addition, the EU Guidelines in the field of environmental exposure to EMF was not implemented at this time, as well. This is very important because the philosophy of the Council Recommendations (CR) $1999 / 519 / \mathrm{EC}$ follows the same structure of the document implementing ELVs (basic restrictions) and ALs (reference levels), only providing more protective safety factors for the general population. The same CR are cited in the Practical Guides of the EU Directive 2913/35/EC for cases when working places are in public areas, and they should be followed for risk assessment in such conditions.

The health policy connected with EMFs' exposure to workers in Europe was developed on the basis of the ICNIRP Guidelines through the implementation of the Directive 2013/35/EC. The transposition of the EU Directive into the national legislation is a large process including the implementation of the new ordinance, training of employers and workers, occupational health services, specialists performing measurements.

Simultaneously, the European recommendations for general population should be implemented by changes in the Health Law, and also by an additional ordinance containing ELVs, ALs, methods for measurement and calculation of EMF parameters, methods for providing compliance, uncertainty, etc.

An additional activity is the development of standard methods of risk assessment for practical implementation valid for concrete occupations and workplaces. Special attention should be paid to workplaces with magnetic resonance imaging.

\subsection{Equipment for measurement of the EMF parameters}

Full set of equipment for measurement of EMF parameters in the working and living environment is available only in NCPHA. These measuring devices are for the frequency range from o to $50 \mathrm{GHz}$, also for different dynamic ranges and sensibility - different for application in occupations and residential areas.

Several devices (about 10) for measurement of EMF are available in Regional Health Inspectorates, also in few control bodies. Unfortunately, most of 
them are with high sensitivity, i.e. for compliance to low exposure limits (living environment), not for workplaces. Some of the devices available in control bodies give a shape form of the frequency dependence which means that such device gives results in per cent of the curve of ALs, not in real EMF parameters. That is also a serious problem.

\section{MAIN RECOMMENDATIONS}

\subsection{In the field of measurements and exposure assessment}

The Practical Guide for good practice, Volume 1, gives an algorithm how to minimize this uncertainty [5].

Firstly, the control body should understand the physical quantity of interest - electric, magnetic or both. It determines the type of instrument required to perform measurements.

Secondly, one should know if the field varies as a continuous wave at one frequency or if it is a complex waveform consisting of multiple frequencies. This determines also the type of instrument required to perform measurements. Simple sinusoidal waveforms at one particular frequency may be assessed using simple broadband instruments and the results compared directly with ALs. Complex waveforms may require the application of sophisticated spectral techniques to identify the various frequency components and complex analyses such as root mean squared (RMS), Peak or Weighted Average approaches for comparison with the ALs.

The next step is to determine the spatial characteristics or if the field varies in strength across the location of interest in which case the exposure is likely to be non-uniform.

The final step before measurement is to know the temporal characteristics of the exposure - does the field vary in frequency and or strength during the operation cycle?

Exposure assessment can be performed in compliance with the ELVs that are very difficult because most of the parameters defining ELVs are immeasurable quantities.

Calculation for compliance with ELVs can be made in accordance with EU Standards 50413 Basic standard on measurement and calculation procedures for human exposure to electric, magnetic and electromagnetic fields $(\mathrm{O} \mathrm{Hz}-30 \mathrm{O} \mathrm{GHz})$ or by using the Practical Guide Vol. 1.

\subsection{In the field of the risk management policy and legislation}

First of all, there is a need for training and education of specialists in the field of measurement and exposure assessment of EMF in the working environment. Our opinion is that the competent specialists performing measurements should be guided by the Ministry of Health (resp. NCPHA), and their competence must be checked every year including calibration of the equipment and testing the knowledge.

Second, it is important that the changes in the Health Law concerning the EMF exposure to general population are adopted by the Parliament, and the Ordinance implementing ELVs and ALs for environmental exposure should be accepted.

Training of control bodies of the Ministry of Labour and Social Affairs, the Regional Health Inspectorates, occupational health services, employers, working committees, trade unions should be performed to manage the risk policy and control concerning the legislation of EMF exposure to workers and population.

A major role in this process must be played by the Expert Consultant Body of the Ministry of Health, also NCPHA as a referent and arbitrary group of the same ministry.

An important activity of the NCPHA can be the collection of data of exposure in a national level for provision data for risk assessment in different occupations.

Developing standard methods for measurement and exposure assessment on the basis of experience is a good practice for reducing the uncertainty in the area of risk evaluation.

Such data exist in NCPHA for most of the occupations. New data with exposure assessment of EMF according to the Ordinance RD-07-5 for the minimal requirements for providing health and safety at work at risks by exposure to electromagnetic fields are available for magnetic resonance imaging technology used in hospitals collected on the basis of new developed methodology by the team at NCPHA methodology.

\subsection{Example: Magnetic resonance imaging} (MRI) data

MRI is a complex source emitting in several frequency ranges. It could be characterized with the inhomogeneous distribution of EMF; large gradients of the magnetic field occurring in the shielded/procedure chamber. All these factors make the assessment of exposure in the work environment extremely complicated.

The main sources of non-ionizing radiations in MRI are as follows:

- $\quad$ Magnet - the largest part of MR system; frequency o Hz; allows the orientation of the hydrogen nuclei in the body. MR medical equipment typically applies static magnetic fields from $0.2 \mathrm{~T}$ to $3 \mathrm{~T}$.

- $\quad$ Gradient system - generates varying magnetic field $(0.5-5 \mathrm{kHz})$. It is used to determine the speed of measurement and spatial resolution. It locates the part of the body to be measured. It consists of an amplifier and gradient coil system. Gradient systems generate low frequency magnetic pulses with complex signal shape that vary depending on the type of scan performed. 
- $\quad R F$ system (10 to $100 \mathrm{MHz}$ ) - it could be differentiated by transmitting and receiving parts of the system. The transmitting part consists of an amplifier and antenna which creates pulses for deflecting the hydrogen nuclei from their orientation. The receiving part consists of receiving antennae that detect signals emitted by the body tissues and convert them for further processing.

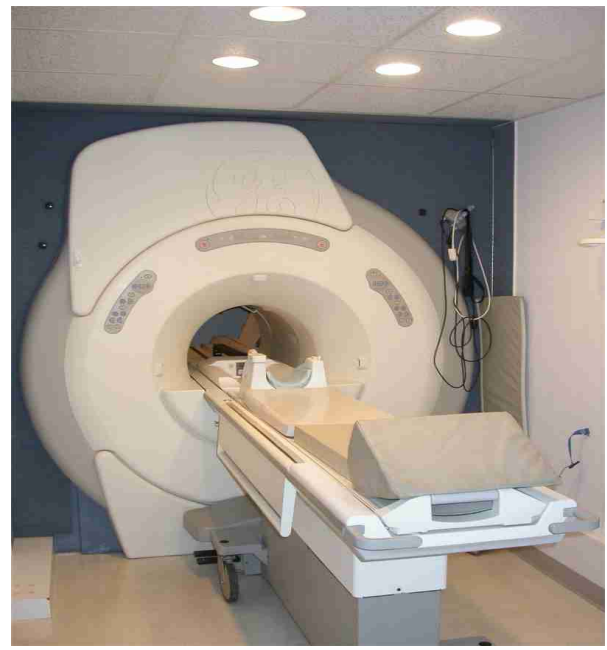

Figure 1. MRI scanner

This requires measurements and evaluation of the electromagnetic field in the following frequency ranges: static (permanent) magnetic field; extremely low frequency (ELF), low frequency (LF) and radio frequency (RF).

The measurements were performed using the following measurement equipment:

- Holaday Industries HI 3550, USA, with, frequency range from $3 \mathrm{MHz}$ up to $18 \mathrm{GHz}$;

- Holaday Industries HI3604, USA with anisotropic probe, frequency range from 20 $\mathrm{Hz}$ to $2 \mathrm{kHz}$ for electric field; from $20 \mathrm{~Hz}$ to 1 $\mathrm{kHz}$ for magnetic field;

- Holaday Industries HI3603, USA with anisotropic probe, frequency range from 2 $\mathrm{kHz}$ to $300 \mathrm{kHz}$ for electric field; from $8 \mathrm{kHz}$ to $300 \mathrm{kHz}$ for magnetic field;

- NARDA EMR 21C, NARDA Safety Test Solutions, Germany, with isotropic probe type 18 , frequency range from $100 \mathrm{kHz}$ up to $3 \mathrm{GHz}$.

- NFM1, Pracitronik, Germany, with anisotropic probe, frequency range $60 \mathrm{kHz}$ up to $350 \mathrm{MHz}$.

Workplaces in 7 medical centers with $1.5 \mathrm{~T}$ MRI equipment were investigated. For each MRI, two premises were studied: shielded/procedure chamber where a medical personnel could be present to assist children or a patient in a severe condition, to give contrast agent or anesthesia; and also a command room with a control panel for MRI.
The measurements of magnetic flux density and electric field strengths generated by the MRI equipment are performed at different distances from the source to obtain their distribution in the shielded chamber taking into account the spatial distribution of the field at the points of measurement. The measurements are performed in the most typical modes/sequences of operation of MRI using a phantom of a head. A system view is carried out to assess the location of the MRI in the shielded room, and the possible access of the personnel. The on-site staff specified the procedures applied and the possible exposure scenarios. Account was taken of the procedures with the highest risk of exposures concerning ELVs.

Figure 2 shows results of measurements of static magnetic field.

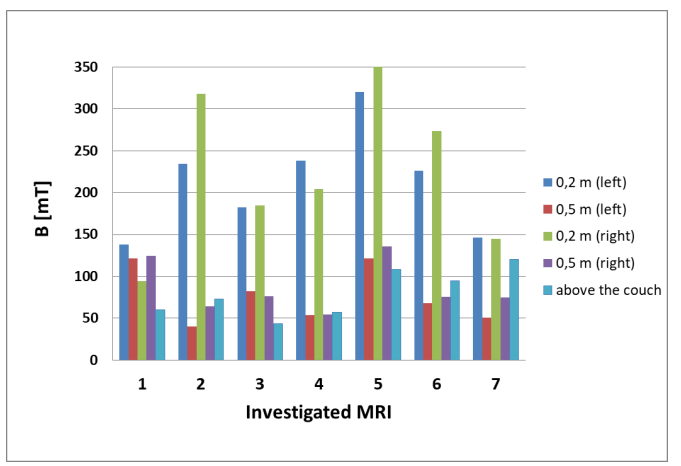

Figure 2. Measured values of magnetic flux density of static field in procedure chamber

The analysis of the results of the carried out measurements and assessments show the following:

Magnetic flux densities don't exceed the sensory and health effects' ELVs, respectively, $2 \mathrm{~T}$ and $8 \mathrm{~T}$ according to Ordinance RD-07-5 of 15 November 2016, in all studied premises. In all shielded chambers the ALs for magnetic flux density for interference with active implanted devices $(0.5 \mathrm{mT})$ and for attraction and projectile risk $(3 \mathrm{mT})$ are exceeded with exception of single points near the doors and windows for observation. Such values are not registered outside the shielded chamber.

The magnetic flux densities and electric field strengths in ELF, $L F$ and $R F$ ranges are below the ALs for thermal and non-thermal effects, respectively, in both types of premises.

The electric field strength and magnetic flux density at $50 \mathrm{~cm}$ from VDU screens are within the $A L s$ for all installations. They also correspond to the requirements for EMR according to technical emission limits MPR II.

The obtained results show that the magnetic flux densities and electric field strengths do not exceed the ALs set out in Annex 2 and Annex 3 of Ordinance RD07-5/ 2016 at the measuring points which according to Art. 8. That means, ELVs for sensory and health effects are not exceeded. 
Although the ALs for magnetic flux density for interference with active implanted devices and for attraction and projectile risk are exceeded in the shielded room, this does not mean that ELVs are exceeded.

Despite the fact that the measured static magnetic field values are lower than the ELVs, any movement in this condition may lead to high induced electrical fields due to the field gradient.

The received results show the presence of risk for workers carrying active and passive implants, carrying medical devices on their body (pumps) and pregnant women.

Taking into account the received results recommendations to the employer are given including access to the shielded chamber; safety signs, stay and movement in the chamber; how to avoid projectile risk, health surveillance, training of the personnel, dealing with workers at specific risk.

Acknowledgements: We would like to express our gratitude to Dr. A. Kunchev, the main governmental health inspector, for the adequate support and policy in the field of implementation of the EU legislation in Bulgaria. Acknowledgments to Hr. Petkova for the design of the poster; and to Iv. Topalova for participation in all measurements of EMF in hospitals.

\section{REFERENCES}

1. "Guidelines for limiting exposure to time-varying electric, magnetic and electromagnetic fields (up to $300 \mathrm{GHz}$ )," Health Phys., vol. 74, no 4, pp. $494-522$, Apr. 1998. PMID: 9525427

2. "Guidelines on limits of exposure to static magnetic fields," Health Phys., vol. 96, no 4, pp. 504-514, Apr. 2009.

DOI: 10.1097/01.HP.0000343164.27920.4a

PMID: 19276710
3. "Guidelines for limiting exposure to time-varying electric and magnetic fields $(1 \mathrm{~Hz}-100 \mathrm{kHz})$," Health Phys., vol. 99, no 6, pp. 818 - 836, Dec. 2010.

DOI: 10.1097/HP.obo13e3181fo6c86

PMID: 21068601

4. Министерство на труда и социалната политика. (15.11.2016). Наредба № рд-о7-5 от 15 ноември 2016 г. за минималните изисквания за осигуряване на здравето и безопасността на работещите при рискове, свързани с експозиция на електромагнитни полета. (Ministry of the Labor and Social Policy. (Nov. 15, 2016). Наредба Ordinance $R D-07-5$ on the minimal requirements for providing health and safety at work at risks by exposure to electromagnetic fields)

Retrieved from: http://dv.parliament.bg/DVWeb/broe veList.faces\#;

Retrieved on: May 14, 2018

5. Non-binding guide to good practice for implementing Directive 2013/35/EU: Electromagnetic fields, vol. 1, European Commission, Luxembourg, 2015.

Retrieved from: http://bookshop.europa.eu/en/nonbinding-guide-to-good-practice-for-implementingdirective-2013-35-eu-electromagnetic-fieldspbKE0415140/; Retrieved on: May 14, 2018

6. Non-binding guide to good practice for implementing Directive 2013/35/EU: Electromagnetic fields, vol. 2, European Commission, Luxembourg, 2015.

Retrieved from: https://publications.europa.eu/en/pu blication-detail/-/publication/e71e8b3f-8775-11e5b8b7-01aa75ed71a1;

7. Non-binding guide to good practice for implementing Directive 2013/35/EU, Electromagnetic fields, Guide for SMEs, European Commission, Luxembourg, 2015. Retrieved from: https://publications.europa.eu/en/pu blication-detail/-/publication/c5fb1d53-8775-11e5b8b7-01aa75ed71a1;

Retrieved on: May 14, 2018 